\title{
One-year urinary and sexual outcome trajectories among prostate cancer patients treated by radical prostatectomy: a prospective study
}

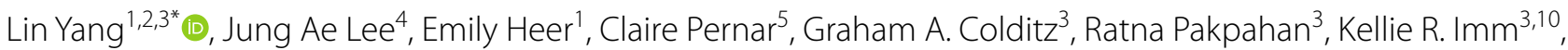
Eric H. Kim, Robert L. Grubb III ${ }^{6,7}$, Kathleen Y. Wolin ${ }^{8}$, Adam S. Kibel ${ }^{9}$ and Siobhan Sutcliffe ${ }^{3}$

\begin{abstract}
Background: To examine one-year trajectories of urinary and sexual outcomes, and correlates of these trajectories, among prostate cancer patients treated by radical prostatectomy (RP).

Methods: Study participants were recruited from 2011 to 2014 at two US institutions. Self-reported urinary and sexual outcomes were measured at baseline before surgery, and 5 weeks, 6 months and 12 months after surgery, using the modified Expanded Prostate Cancer Index Composite-50 (EPIC-50). Changes in EPIC-50 scores from baseline were categorized as improved (beyond baseline), maintained, or impaired (below baseline), using previously-reported minimum clinically important differences.

Results: Of the 426 eligible participants who completed the baseline survey, 395 provided data on at least one EPIC-50 sub-scale at 5 weeks and 12 months, and were analyzed. Although all mean EPIC-50 scores declined markedly 5 weeks after surgery and then recovered to near (incontinence-related outcomes) or below (sexual outcomes) baseline levels by 12 months post-surgery, some men experienced improvement beyond their baseline levels on each sub-scale (3.3-51\% depending on the sub-scale). Having benign prostatic hyperplasia (BPH) at baseline (prostate size $\geq 40$ g; an International Prostate Symptom Index Score $\geq 8$; or using BPH medications) was associated with postsurgical improvements in voiding dysfunction-related bother at 5 weeks $(\mathrm{OR}=3.9,95 \% \mathrm{Cl}: 2.1-7.2)$ and 12 months $(\mathrm{OR}=3.3,95 \% \mathrm{Cl}: 2.0-5.7)$; and in sexual bother at 5 weeks $(\mathrm{OR}=5.7,95 \% \mathrm{Cl}: 1.7-19.3)$ and 12 months $(\mathrm{OR}=3.0,95 \%$ Cl: 1.2-7.1).
\end{abstract}

Conclusions: Our findings provide additional support for considering baseline BPH symptoms when selecting the best therapy for early-stage prostate cancer.

Keywords: Localized prostate cancer, Benign prostatic hyperplasia, Radical prostatectomy, Urinary outcome, Sexual outcome

*Correspondence: Lin.Yang@albertahealthservices.ca

${ }^{1}$ Department of Cancer Epidemiology and Prevention Research, Cancer Research and Analytics, Cancer Care Alberta, Alberta Health Services, 5th Floor, Holy Cross Centre, Box ACB, 2210 - 2 St. SW, Calgary, AB T2S 3C3, Canada

Full list of author information is available at the end of the article

\section{Background}

Early-stage, localized prostate cancer can be managed in several ways, including watchful waiting, active surveillance, and curative modalities such as radical prostatectomy (RP), external radiotherapy, and brachytherapy. As each of these modalities has high survival rates [1], the 
benefits of curative therapies must be carefully weighed against their harms, including their side effects [2-4].

A number of studies have documented the natural history of prostate cancer treatment side effects [5-12]. For $R P$, in particular, studies indicate that men tend to experience an initial large decline in urinary and sexual function immediately after surgery (i.e., within the first two months), followed by a gradual improvement to near or below baseline levels by the first year post-surgery. One exception to this pattern is voiding dysfunction (or urinary irritation or obstruction). Symptoms of voiding dysfunction have been observed to improve beyond pre-surgical values in a few previous studies, presumably because of relief of urinary obstruction by prostatectomy in men with both prostate cancer and benign prostatic hyperplasia (BPH) [13]. These findings have led AUA, ASTRO, and SUO to recommend surgery over radiation therapy for patients with clinically localized prostate cancer and obstructive, non-cancer-related lower urinary tract dysfunction [14]. However, as this recommendation is Grade $\mathrm{C}$, additional high-quality evidence from randomized controlled trials and prospective observational studies is still needed.

To our knowledge, voiding dysfunction is the only outcome in which improvement beyond pre-surgical values has been explored. Although mean improvement has not been observed in other outcomes, such as sexual function or bother, it is possible that examination of mean trajectories may have obscured improvement or other trajectories experienced by only a subset of participants-for instance, those who use medication and devices to treat their erectile dysfunction (ED) after surgery. Understanding the full range of side effect trajectories would be useful to help set patients' expectations post-surgery and to further aid with treatment decision-making. Therefore, we analyzed data from the prospective Prostatectomy, Incontinence, and Erectile Dysfunction (PIE) Study to describe the full range of urinary and sexual side effect trajectories, the percentage of patients with improvement beyond baseline in each domain, and factors related to improvement in the first year post-surgery (i.e. BPH- and ED-related factors).

\section{Methods}

\section{Study population and design}

Prostate cancer patients were recruited into the PIE study from 2011 to 2014 at two sites, Washington University School of Medicine and Brigham \& Women's Hospital. All men undergoing RP for clinically localized prostate cancer were eligible, except for those who: (1) had previously undergone treatment for prostate cancer, radiation therapy to the pelvis (including bladder, rectum, or prostate), or major pelvic surgery (including penile implant or urinary sphincter); (2) had known urethral stricture or colostomy; (3) were unable to urinate and required indwelling catheterization; and (4) did not speak English. Men who received neo-adjuvant therapy or any additional prostate cancer-related therapies (e.g., radiation or hormonal therapies) during the one-year study followup were excluded from the analyses. The PIE study was approved by the institutional review boards at both institutions. All participants provided informed consent.

\section{Urinary and sexual outcomes}

Patient-reported urinary and sexual outcomes were assessed at baseline before RP, and 5 weeks, 6 months, and 12 months post-RP by the modified Expanded Prostate Cancer Index Composite-50 (EPIC-50) [15]. This validated scale includes sub-scales for urinary function (i.e., continence), urinary bother, sexual function, and sexual bother. We split the urinary bother scale into two sub-scales to distinguish incontinence-related bother from voiding dysfunction-related bother [16]. For each EPIC-50 sub-scale, a summary score was calculated and then transformed linearly to a 0 -to- 100 scale, with higher scores indicating better function and less bother.

\section{Demographic and lifestyle factors}

Before RP, participants completed a baseline questionnaire including items on age, education, household income, race/ethnicity, insurance status, and marital status, as well as lifestyle factors, such as cigarette smoking history. Self-reported data on frequency of performing pelvic floor (i.e., Kegel) exercises after RP was ascertained on the follow-up questionnaires.

\section{$\mathrm{BPH}$ - and ED-related factors}

We abstracted data on clinical characteristics from participants' medical charts. These included comorbidities (Charlson Comorbidity Index), prostate cancer characteristics (pre-surgical clinical staging, prostate-specific antigen [PSA] concentration, and post-surgical pathological staging); pre-surgical urological conditions, including BPH (prostate size measured from the RP specimen, International Prostate Symptom Index [IPSS], and selfreported BPH medication use [overall, $\alpha$-blocker use only, and $5 \alpha$-reductase inhibitor use with or without $\alpha$-blockers]); surgical characteristics taken from the operative note (blood loss during surgery, attempted number of neurovascular bundles preserved, type of surgical procedure, and bladder neck reconstruction), and sexual dysfunction therapies (pre- and post-surgical ED medication and device use). 


\section{Statistical analysis}

To begin to explore and display the distributions of urinary and sexual outcomes over time, we constructed boxplots with lines connecting the mean values from baseline through 12 months. This display is similar to figures presented in previous analyses of post-RP outcomes. Next, we investigated side effect trajectories by calculating the difference in each urinary and sexual outcome between baseline and 12 months for each participant and then by ranking participants according to their magnitude of change for each outcome (i.e., from the minimum to the maximum). To illustrate these trajectories, we selected a sample of participants (i.e., those ranked at the 5th, 25th, 50th, 75th, and 95th percentiles) for each outcome and plotted each participant's change from baseline through 12 months, analogous to a selective "spaghetti plot".

Given that some changes may be too small to be meaningful to patients, we next categorized both shortand long-term changes (from baseline to 5 weeks and 12 months, respectively) into clinically meaningful categories, using sub-scale-specific minimum clinically important difference (MCID) ranges reported by Skolarus and colleagues [17]. The upper bounds of these subscale-specific ranges were chosen to obtain conservative estimates: i.e., 9 point change in the urinary domain (7 for voiding dysfunction-related symptoms) and 12-point change in the sexual domain [17]. We used these subscale-specific values to create the following categories of change: improved beyond baseline (positive change greater than the MCID), maintained (within the positive to negative values of the MCID), and impaired below baseline (negative change greater than the MCID) [16, 18]. We also used the lower bounds of sub-scale-specific ranges to classify participants in sensitivity analyses.

Multinomial logistic regression was used to explore $\mathrm{BPH}$ - and ED-related factors associated with short- and long-term improvement beyond baseline and maintenance in urinary and sexual outcomes (in sub-scales with at least 10 men for stable estimation). Factors considered were individual measures of $\mathrm{BPH}$ (pre-surgical prostate size, IPSS score, and reported use of BPH medications, overall and separately by type), as well as a composite $\mathrm{BPH}$ outcome (prostate size $\geq 40 \mathrm{~g}$ [19], IPSS score $\geq 8$ [20], or medication use), and measures of sexual dysfunction (pre- and post- surgical ED medication and device use). Sensitivity analyses were performed by: (1) adjusting for factors significantly associated with improvement or maintenance in at least one urinary or sexual outcome; (2) using the lower bounds of the EPIC-50 sub-scale-specific MCID ranges to classify participants; (3) excluding men with pre-surgical EPIC-50 scores too high to experience improvement (i.e., higher than the value obtained by subtracting the sub-scale specific MCID from 100); (4) restricting to men with complete data on specific urinary and sexual outcomes at baseline, 5 weeks and 12 months; and (5) repeating the analyses using the 6 month followup data.

\section{Results}

Participant characteristics

Of the 426 eligible participants who completed the baseline survey, 395 (92.7\%) provided data on at least one EPIC-50 sub-scale at baseline, 5 weeks, or 12 months, and were included in the analysis. The majority of included participants (mean age $=60.7$ years) were Caucasian (91.9\%), had completed at least some college education (83.6\%), earned $\geq \$ 75,000$ per year $(61.4 \%)$, were married or living with a partner $(82.5 \%)$, and had never smoked (62.5\%, Table 1). Among participants with data on the Charlson Comorbidity Index $(n=167), 103(61.7 \%$ of 103 and $26.2 \%$ of 394 ) had at least one comorbidity. Considering their prostate cancer-specific characteristics, most participants had clinical stage T1 (78.5\%) and pathologic stage T3 (88.9\%) disease, with a pre-surgical PSA concentration between 4 and $10 \mathrm{ng} / \mathrm{mL}$. The majority $(92.3 \%)$ of men underwent a minimally-invasive RP and $65.2 \%$ had a bilateral never-sparing procedure.

\section{Changes in urinary and sexual outcomes}

With respect to urinary incontinence, most men had high function (mean =93.1) and bother scores (mean =95.8, i.e., good function and not much bother) at baseline. Scores for voiding dysfunction-related bother were also high $($ mean $=74.5)$, but lower than for incontinencerelated bother. With respect to sexual outcomes, baseline levels were lower than for urinary outcomes, and were also lower for sexual function (mean =56.2) than for bother $($ mean $=68.9)$, indicating worse sexual function but not as much bother (Fig. 1a-e). Five weeks after surgery, mean levels of each of these outcomes were markedly decreased. For urinary incontinence-related outcomes, levels recovered to near, but below, baseline 6 months post-surgery and then slowed to a plateau by 12 months. In contrast, for voiding dysfunction-related bother, levels recovered to above baseline 6 months postsurgery and then remained relatively constant through 12 months. Finally, for sexual-related outcomes, mean levels remained well below baseline but continued to improve gradually through 12 months post-surgery.

When individual trajectories of change were examined, a generally similar impression of symptom change was obtained, particularly when viewing the median $\left(50^{\text {th }}\right)$ percentile trajectories (Fig. 2a-e). However, these displays also highlighted improved (beyond baseline) or maintained outcomes in all domains over time. Improvement was greatest for voiding dysfunction-related bother 
Table 1 Socio-demographic, lifestyle, and clinical characteristics of prostate cancer patients in the prostatectomy, incontinence and erectile dysfunction (PIE) study

\begin{tabular}{|c|c|c|}
\hline & $\mathbf{N}$ & $\%$ or mean $(\mathrm{SD})$ \\
\hline \multicolumn{3}{|l|}{ Socio-demographic and lifestyle factors } \\
\hline Age (years, mean, SD) & 395 & $60.7(6.9)$ \\
\hline Caucasian (\%) & 385 & 91.9 \\
\hline Education (\%) & 385 & \\
\hline High school degree or less & & 16.4 \\
\hline Some college & & 30.9 \\
\hline College degree & & 23.9 \\
\hline Post graduate & & 28.8 \\
\hline Household income (\%) & 365 & \\
\hline$<\$ 50,000$ & & 18.3 \\
\hline$\$ 50,000-<\$ 75,000$ & & 20.3 \\
\hline$\geq \$ 75,000$ & & 61.4 \\
\hline Married or living with a partner (\%) & 395 & 82.5 \\
\hline Smoking (\%) & 385 & \\
\hline Never smoker & & 62.5 \\
\hline Former smoker & & 32.7 \\
\hline Current smoker & & 6.8 \\
\hline Charlson Comorbidity Index (\%) & 394 & \\
\hline No comorbidities & & 16.2 \\
\hline Any comorbidities & & 26.2 \\
\hline Missing & & 57.6 \\
\hline \multicolumn{3}{|l|}{ Prostate cancer-and surgery-related factors } \\
\hline Clinical T1 stage (\%) & 381 & 78.5 \\
\hline Pathological stage (\%) & 389 & \\
\hline $\mathrm{T} 2$ & & 11.1 \\
\hline $\mathrm{T} 3$ & & 88.9 \\
\hline $\begin{array}{l}\text { Pre-surgical prostate-specific antigen concentra- } \\
\text { tion }(\mathrm{ng} / \mathrm{mL} \text {, mean, SD) }\end{array}$ & 393 & $6.3(4.6)$ \\
\hline Blood loss during surgery (mL, mean, SD) & 358 & $246.3(203.3)$ \\
\hline Neurovascular bundle preservation (\%) & 351 & \\
\hline Non-nerve sparing & & 19.4 \\
\hline Unilateral neurovascular bundle spared & & 15.4 \\
\hline Bilateral nerve sparing & & 65.2 \\
\hline Surgical procedure (\%) & 365 & \\
\hline Minimally-invasive (robotic and laparoscopic) & & 92.3 \\
\hline Open & & 7.7 \\
\hline Bladder reconstruction & 364 & 53.0 \\
\hline \multicolumn{3}{|l|}{ BPH-related factors } \\
\hline Prostate size (grams, mean, SD) & 288 & $43.5(16.6)$ \\
\hline IPSS score at baseline (mean, SD) & 249 & $8.6(6.7)$ \\
\hline BPH medication use at baseline (\%) & 395 & 13.2 \\
\hline a-blocker use & & 10.4 \\
\hline 5a-reductase inhibitor (and a-blocker) use & & 2.8 \\
\hline \multicolumn{3}{|l|}{ Urinary and sexual function-related factors } \\
\hline \multicolumn{3}{|l|}{ Reported Kegel exercises } \\
\hline 5 weeks post-surgery & 358 & 67.3 \\
\hline 12 months post-surgery & 332 & 31.3 \\
\hline \multicolumn{3}{|l|}{ ED medication or device use (\%) } \\
\hline Baseline & 365 & 4.8 \\
\hline 5 weeks post-surgery & 365 & 30.1 \\
\hline 12 months post-surgery & 336 & 18.2 \\
\hline
\end{tabular}

Table 1 (continued)

$B P H$ benign prostatic hyperplasia, ED erectile dysfunction, IPSS International Prostate Symptom Score, SD standard deviation

(22.1\% of men at 5 weeks; $50.9 \%$ at 12 months), followed by sexual bother ( $7.3 \%$ at 5 weeks; $10.6 \%$ at 12 months), and urinary function (9.8\% at 12 months, Tables 2 and 3 ). Lesser proportions of men experienced improvement in incontinence-related bother and sexual function $(<5 \%)$. Of note, improvement beyond baseline was observed even as early as 5 weeks post-surgery, particularly for voiding dysfunction-related and sexual bother.

\section{Factors associated with improvement beyond baseline in urinary and sexual outcomes}

No significant associations were observed for $\mathrm{BPH}$ - or ED-related factors with improved or maintained urinary function or incontinence-related bother after surgery (only evaluable at 12 months, Table 2 and Additional file 1: Table 1). In contrast, each of the individual measures of $\mathrm{BPH}$, as well as the $\mathrm{BPH}$ composite measure, were associated with improved voiding dysfunction-related bother at both 5 weeks and 12 months post-surgery (5 weeks: odds ratio $[\mathrm{OR}]=3.9,95 \%$ confidence interval $[\mathrm{CI}]: 2.1-7.2 ; 12$ months: $\mathrm{OR}=3.3,95 \% \mathrm{CI}: 2.0-5.7$ for the $\mathrm{BPH}$ composite measure). No associations were observed for ED medication or device use at baseline or follow-up.

With respect to sexual outcomes, no significant associations were observed for BPH- or ED-related factors with improved or maintained sexual function. In contrast, the $\mathrm{BPH}$ composite measure was associated with improved sexual bother at both 5 weeks $(\mathrm{OR}=5.7,95 \%$ CI:1.7-19.3) and 12 months post-surgery (OR $=3.0,95 \%$ CI: 1.2-7.1, Table 3 and Additional file 1: Table 2). Positive associations were also observed for several of the individual measures of $\mathrm{BPH}$, including $\alpha$-blocker use $(\mathrm{OR}=4.4,95 \% \mathrm{CI}: 1.1-18.0)$ with improvement in sexual function at 12 months post-surgery, and BPH medication use $(\mathrm{OR}=5.4,95 \% \mathrm{CI}: 2.2-13.0)$ and $\alpha$-blocker use $(\mathrm{OR}=5.6,95 \% \mathrm{CI}: 2.2-14.6)$ with improvement in sexual bother at 5 weeks. Finally, an inverse association was observed for ED medication or device use during followup with maintained sexual function $(\mathrm{OR}=0.5,95 \% \mathrm{CI}$ : $0.3-0.9)$ and bother $(\mathrm{OR}=0.5,95 \% \mathrm{CI}: 0.3-1.0)$ compared to impaired function and bother 12 months postsurgery. This is likely due to confounding by indication, whereby men who experienced large declines in sexual function may have been more likely to use ED medications or devices after surgery.

Similar results were observed in sensitivity analyses: (1) adjusting for age, smoking status, living arrangement, and neurovascular bundle preservation; (2) using the lower 

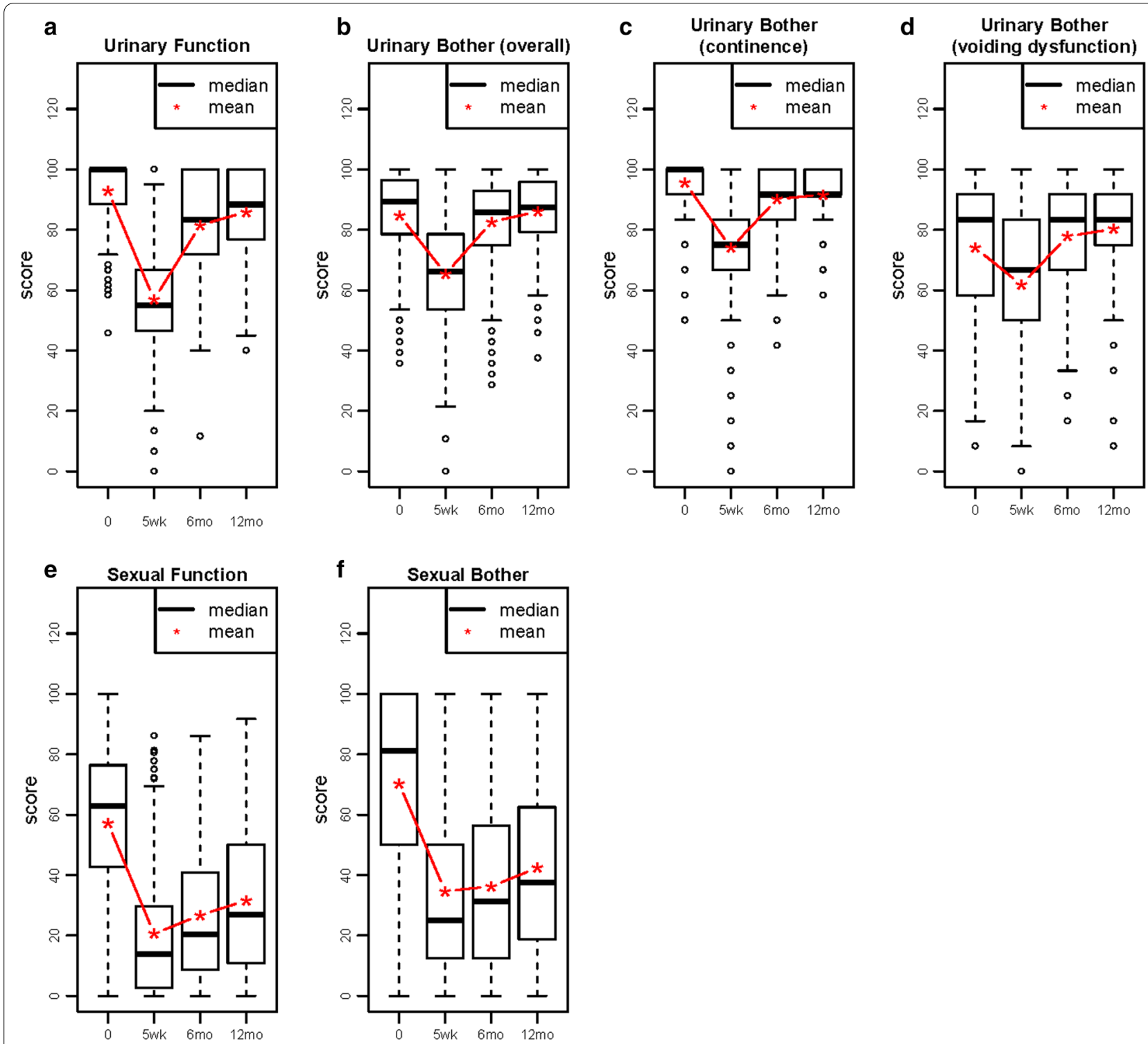

Fig. 1 Changes in Urinary and Sexual Outcomes (mean values) Assessed by the Expanded Prostate Cancer Index Composite (EPIC)-50 among Men in the Prostatectomy, Incontinence and Erectile Function (PIE) Study, between Baseline and 12 Months Post-Radical Prostatectomy

bounds of the EPIC-50 sub-scale-specific MCID ranges; (3) excluding men with high pre-surgical scores in each EPIC-50 sub-scale; (4) restricting to men with complete outcome data at baseline, 5 weeks and 12 months; and (5) examining the 6-month follow-up data (results not shown).

\section{Discussion}

Similar to previous studies, our study demonstrated sharp declines in mean urinary and sexual outcomes 5 weeks post-RP, followed by recovery to near, but below, baseline values for urinary incontinence-related outcomes, and to improved, but well below, baseline values for sexual outcomes. However, by examining individual participant trajectories, we also identified several groups of men who experienced improvement beyond their baseline values in each urinary and sexual outcome. Notably, a considerable proportion of men experienced immediate and long-term improvement in voiding dysfunction-related bother, and a small proportion experienced long-term improvement in urinary function (continence) and sexual bother. To our knowledge, improvement in outcomes besides voiding dysfunction has not previously been documented. Additionally, we found that pre-surgical BPH 

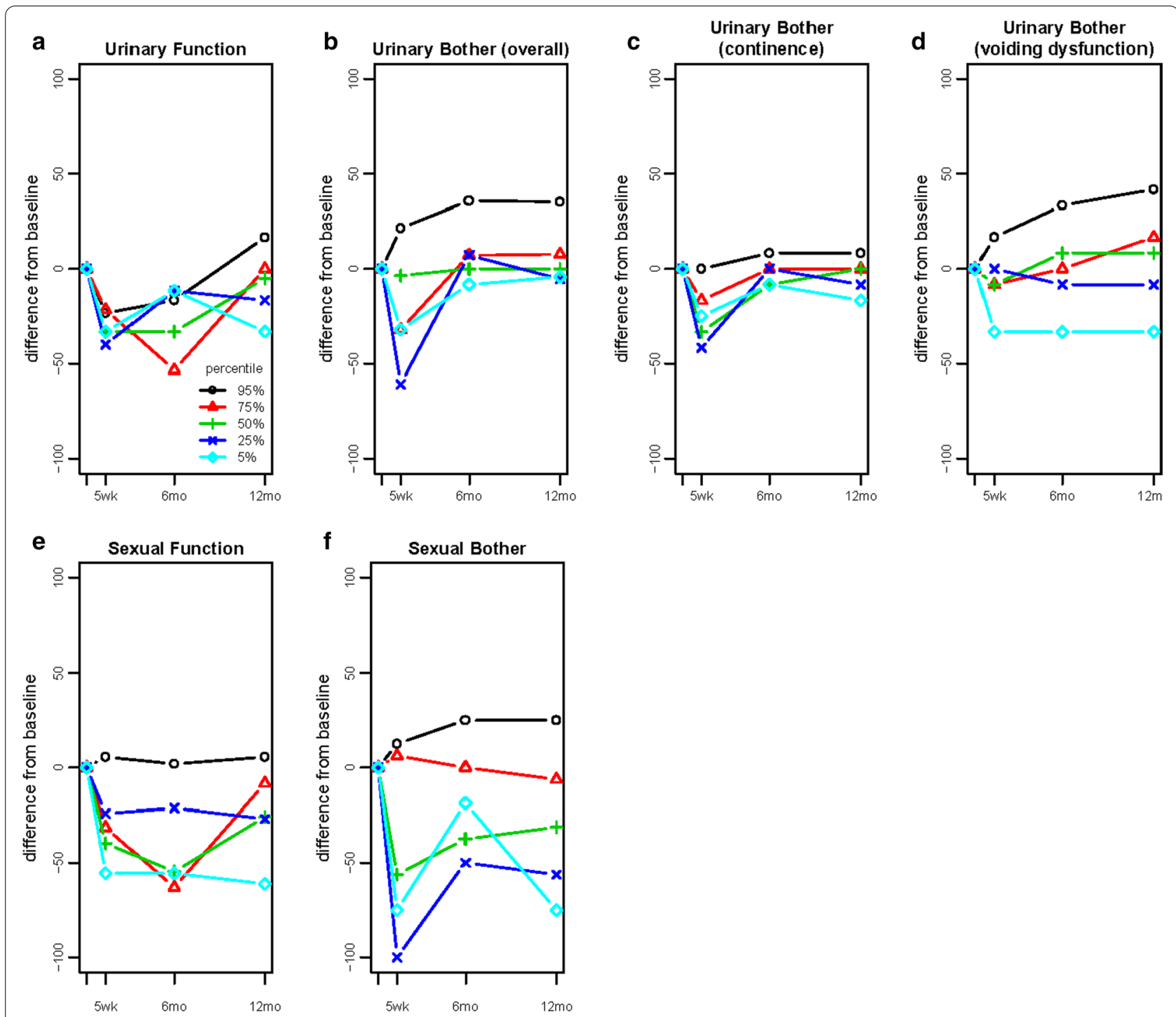

Fig. 2 Individual Trajectories of Urinary and Sexual Outcomes Assessed by the Expanded Prostate Cancer Index Composite (EPIC)-50 among Men in the Prostatectomy, Incontinence and Erectile Function (PIE) Study from Baseline through 12 Months Post-Radical Prostatectomy (The trajectories for five different individuals per domain are presented in each graph. These individuals were selected by subtracting each participant's 12 month follow-up values in each EPIC-50 domain from their baseline values and then by ranking these differences. The outcome trajectories for participants ranked at the $5^{\text {th }}, 25^{\text {th }}, 50^{\text {th }}, 75^{\text {th }}$, and $95^{\text {th }}$ percentiles of change for each domain are presented to illustrate the range of trajectories experienced by participants. In each domain, participants at the $95^{\text {th }}$ percentile experienced improvement)

was associated with improvement beyond baseline in both voiding dysfunction and sexual bother, strengthening the evidence in national urologic oncology guidelines to recommend surgical treatment for appropriate prostate cancer patients with $\mathrm{BPH}$.

Our finding of clinically meaningful improvement in urinary continence among a small proportion of men treated for prostate cancer by RP was unexpected and differs from most previously published findings [10, 21, 22]. One possible explanation for this finding may be surgical elimination of bladder outlet resistance by RP.
Studies of bladder outlet resistance have demonstrated that the bladder detrusor muscle undergoes structural and functional changes, with initial hypertrophy, then compensation, and then decompensation [23-25]. The bladders of men with BPH who undergo RP for prostate cancer may lie anywhere along this spectrum. Men in an initial hypertrophic stage may have some degree of urge-related urinary incontinence, which may be relieved by bladder remodelling following surgical elimination of outlet resistance by RP. Likewise, men in a late decompensated stage may have some degree of stress-related 


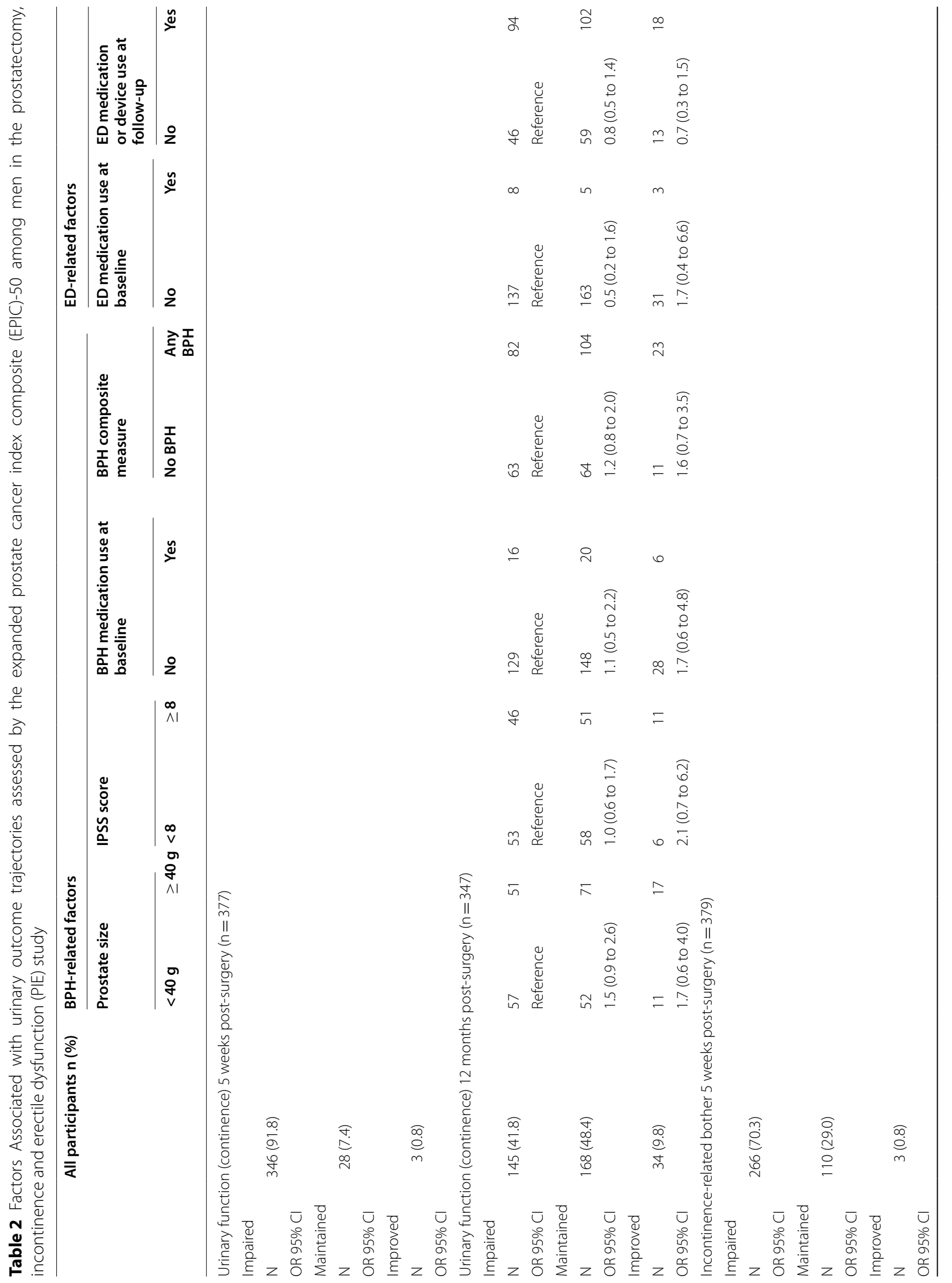




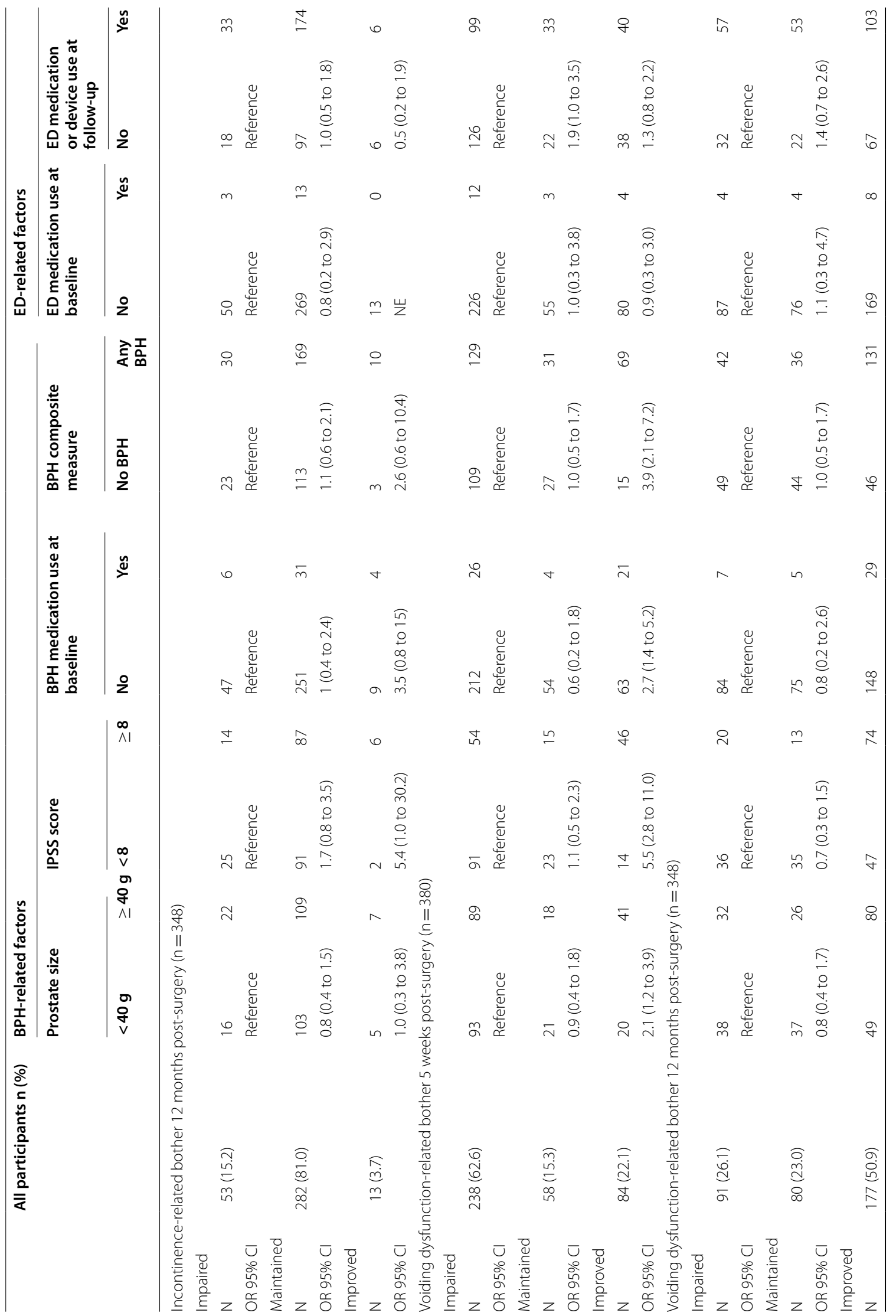




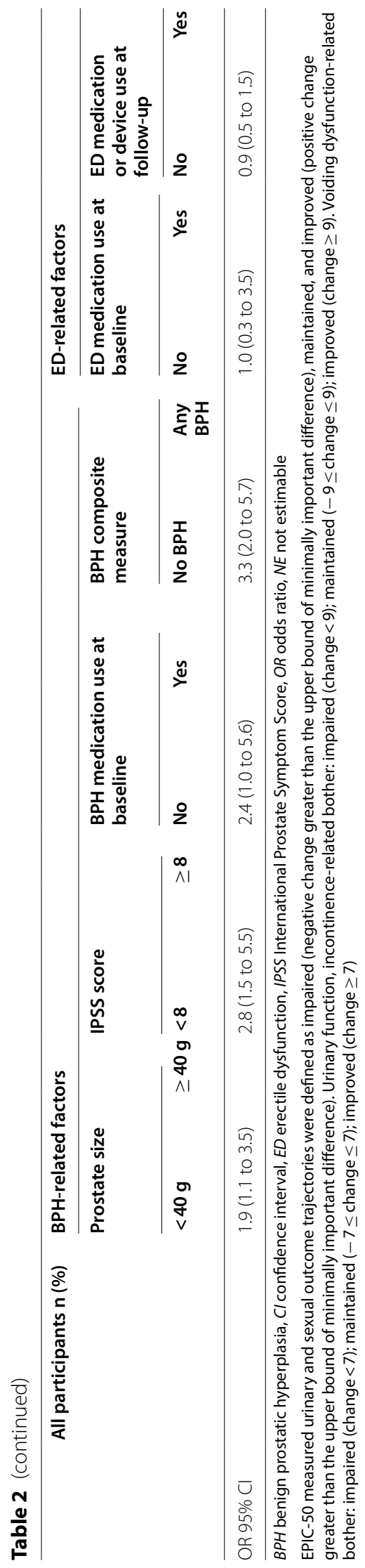




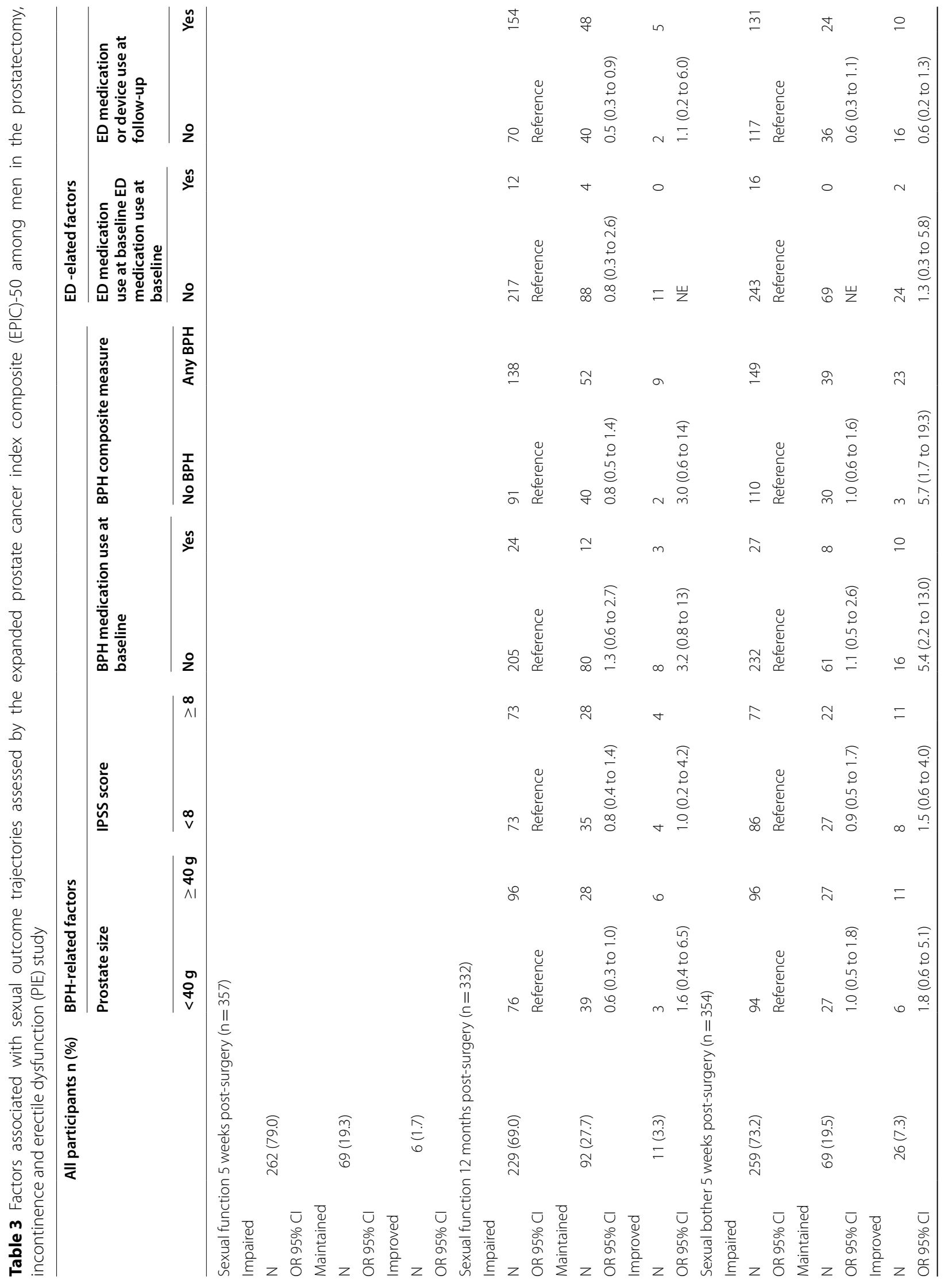




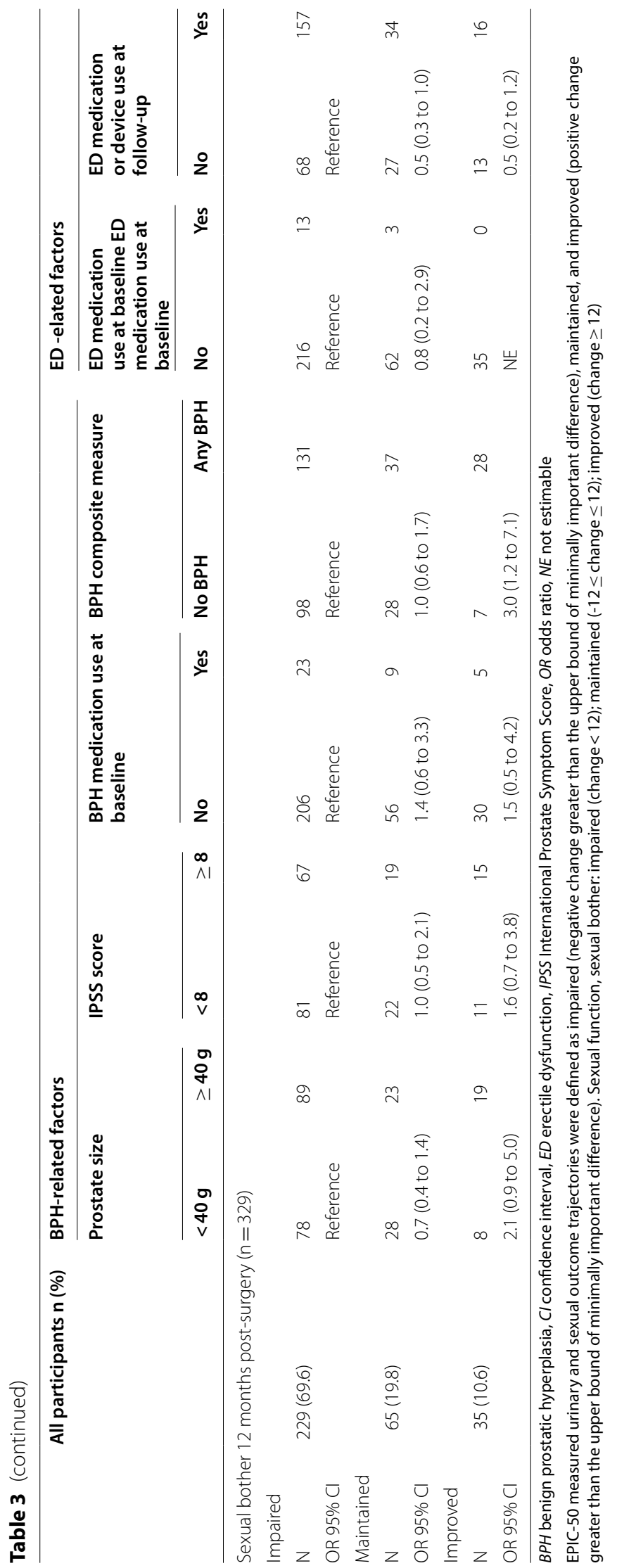


urinary incontinence owing to chronic subclinical urinary retention, which may also be relieved by RP.

An additional unexpected observation was our finding that a small proportion of men who underwent RP experienced improvements beyond baseline in sexual outcomes, particularly long-term sexual bother, independent of ED therapy. Although resolution of neuropraxia might explain recovery in these outcomes to baseline levels, we believe it is unlikely to explain improvements beyond baseline. Another possible explanation is improved communication surrounding sexual function. Prostate cancer treatment and its known sexual side effects may be a launching point for men to have an open conversation with their providers and partners about their sexual function. Previous studies have demonstrated that spousal communication is a key factor in healthy sexual function recovery after prostate cancer treatment [26]. For many men, prostate cancer treatment discussions may prompt discussions regarding sexual function that have not been addressed in the past. The mechanisms through which open communication may improve post-RP sexual outcomes might be similar to those in studies of premenopausal women with dyspareunia, which found that open communication between partners was critical for improving sexual function and distress [27].

Another possible explanation for improvement in sexual bother could be relief of sexual bother related to voiding dysfunction post-RP. This hypothesis is supported by growing evidence that BPH and ED may be caused by common biologic mechanisms [28]. As such, improvements in BPH-related symptoms from RP may also result in improvements in sexual outcomes. Alternatively, certain $\mathrm{BPH}$-related medications are known to be associated with decreased sexual function [29]. Therefore, discontinuation of these drugs may contribute to improvement following RP, as was observed for men taking $\alpha$-blockers pre-RP in our sample. In support of both of these mechanisms, our data demonstrated a higher odds of improved sexual bother associated with the BPH composite index. Finally, it is also possible that RP may relieve sexual pain in men with pre-surgical chronic prostatitis/chronic pelvic pain syndrome, thereby contributing to improvements in sexual bother. Although each of these explanations is speculative, we believe they warrant further study for their possible, eventual guidance for prostate cancer therapeutic decision-making and overall patient counseling.

Strengths of this study include its prospective design, large sample size, frequent follow-up of participants over the one-year study period, and use of validated outcome measures designed specifically for prostate cancer survivors. Additionally, use of the EPIC-50 rather than the shorter EPIC-26 allowed us to gain a more comprehensive understanding of both urinary and sexual function and bother; and our unique statistical analysis allowed us to explore the full range of outcome trajectories rather than just mean outcome levels. However, it is also important to note the limitations of this analysis. Specifically, information on co-existing urological conditions was not collected systematically on all participants, but was only available from participants ' medical records, which may not have had complete information on these conditions. Additionally, data were not collected between 5 weeks and 6 months (e.g., 3 months) to allow us to identify when some outcomes returned to baseline levels.

\section{Conclusions}

We observed improvements in urinary and sexual outcomes among non-trivial proportions of men who underwent RP. Although reasons for improvement in urinary function (continence) and sexual bother are unclear, improvement in voiding dysfunction-related bother likely relates to relief of $\mathrm{BPH}$ symptoms by RP, as prostatectomy is a known, effective therapy for severe $\mathrm{BPH}$. Therefore, our findings provide additional support for considering baseline BPH symptoms when selecting the best therapy for early-stage prostate cancer.

\section{Supplementary Information}

The online version contains supplementary material available at https://doi. org/10.1186/s12894-021-00845-0.

Additional file 1: Supplementary Table 1. Association between Baseline BPH Medication Use with Urinary Outcome Trajectories Assessed by the Expanded Prostate Cancer Index Composite (EPIC)-50 among Men in the Prostatectomy, Incontinence and Erectile Dysfunction (PIE) Study. Supplementary Table 2. Association between Baseline BPH Medication Use with Sexual Outcome Trajectories Assessed by the Expanded Prostate Cancer Index Composite (EPIC)-50 among Men in the Prostatectomy, Incontinence and Erectile Dysfunction (PIE) Study.

\section{Acknowledgements}

We acknowledge all the participants in this study. A part of the analyses was previously presented at the CanPROS Scientific Conference 2019 and published as an abstract on Current Oncology 2020, 27(1),64-71.

\section{Authors' contributions}

All authors contributed to the study conception and design. Material preparation, data collection and analysis were performed by $L Y, J A L, E H, C P, G A C, R P$, KRI, EHK, RLG III, KYW, ASK and SS. The first draft of the manuscript was written by $L Y$ and all authors commented on subsequent versions of the manuscript. All authors read and approved the final manuscript. 


\section{Funding}

The PIE study was supported by the Transdisciplinary Research on Energetics and Cancer (TREC) Center at Washington University in St. Louis. The TREC Center was funded by the National Cancer Institute at NIH (U54 CA155496), Washington University, the Alvin J. Siteman Cancer Center, and the Foundation for Barnes-Jewish Hospital. The funders had no role in the design and conduct of this study nor the collection, management, analysis and interpretation of data.

\section{Availability of data and materials}

The dataset supporting the conclusion of this article is available upon requst.

\section{Declarations}

\section{Ethics approval and consent to participate}

The PIE study was approved by the institutional review boards at Washington University School of Medicine and Brigham \& Women's Hospital. All participants provided written informed consent.

\section{Consent for publication}

Not applicable.

\section{Competing interests}

The authors declare that they have no competing interests.

\section{Author details}

${ }^{1}$ Department of Cancer Epidemiology and Prevention Research, Cancer Research and Analytics, Cancer Care Alberta, Alberta Health Services, 5th Floor, Holy Cross Centre, Box ACB, 2210 - 2 St. SW, Calgary, AB T2S 3C3, Canada. ${ }^{2}$ Departments of Oncology and Community Health Sciences, University of Calgary, Calgary, Canada. ${ }^{3}$ Division of Public Health Sciences, Department of Surgery, Washington University School of Medicine, 600 S. Taylor Ave., 2nd floor, Rm. 208S, Campus Box 8100, St. Louis, MO 63110, USA. ${ }^{4}$ Agricultural Statistics Laboratory, University of Arkansas, Fayetteville, USA. ${ }^{5}$ Department of Epidemiology, Harvard T.H. Chan School of Public Health, Boston, MA, USA. ${ }^{6}$ Division of Urological Surgery, Department of Surgery, Washington University School of Medicine, St Louis, USA. ${ }^{7}$ Department of Urology, Medical University of South Carolina, Charleston, USA. ${ }^{8}$ Coeus Health, Chicago, IL, USA. ${ }^{9}$ Division of Urology, Department of Surgery, Brigham and Women's Hospital, Boston, USA. ${ }^{10}$ Division of Health Behavior Research, Department of Preventive Medicine, Keck School of Medicine of theUniversity of Southern California, $2001 \mathrm{~N}$ Soto St., Los Angeles, CA 90032, USA.

Received: 2 September 2020 Accepted: 28 April 2021

Published online: 17 May 2021

\section{References}

1. Lin GA, Aaronson DS, Knight SJ, Carroll PR, Dudley RA. Patient decision aids for prostate cancer treatment: a systematic review of the literature. CA Cancer J Clin. 2009;59(6):379-90.

2. Barry MJ. Quality of life and prostate cancer treatment. J Urol. 1999;162(2):407.

3. Sanda MG, Dunn RL, Michalski J, Sandler HM, Northouse L, Hembroff L, Lin X, Greenfield TK, Litwin MS, Saigal CS, et al. Quality of life and satisfaction with outcome among prostate-cancer survivors. N Engl J Med. 2008;358(12):1250-61

4. McNutt RA. Shared medical decision making: problems, process, progress. JAMA. 2004;292(20):2516-8.

5. Ferrer M, Suarez JF, Guedea F, Fernandez P, Macias V, Marino A, Hervas A,

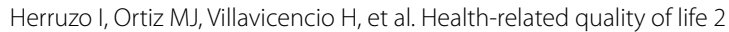
years after treatment with radical prostatectomy, prostate brachytherapy, or external beam radiotherapy in patients with clinically localized prostate cancer. Int J Radiat Oncol Biol Phys. 2008;72(2):421-32.
6. Tseng TY, Kuebler HR, Cancel QV, Sun L, Springhart WP, Murphy BC, Albala DM, Dahm P. Prospective health-related quality-of-life assessment in an initial cohort of patients undergoing robotic radical prostatectomy. Urology. 2006;68(5):1061-6.

7. Muramaki M, Miyake H, Behnsawy HM, Furukawa J, Harada K, Fujisawa M. Assessment of postoperative quality of life: comparative study between laparoscopic and minimum incision endoscopic radical prostatectomies. Int J Clin Oncol. 2014;19(6):1092-7.

8. Willis DL, Gonzalgo ML, Brotzman M, Feng Z, Trock B, Su LM. Comparison of outcomes between pure laparoscopic vs robot-assisted laparoscopic radical prostatectomy: a study of comparative effectiveness based upon validated quality of life outcomes. BJU Int. 2012;109(6):898-905.

9. Parker WR, Wang R, He C, Wood DP Jr. Five year expanded prostate cancer index composite-based quality of life outcomes after prostatectomy for localized prostate cancer. BJU Int. 2011;107(4):585-90.

10. Miyake H, Miyazaki A, Furukawa J, Hinata N, Fujisawa M. Prospective assessment of time-dependent changes in quality of life of Japanese patients with prostate cancer following robot-assisted radical prostatectomy. J Robot Surg. 2016;10(3):201-7.

11. Pardo Y, Guedea F, Aguilo F, Fernandez P, Macias V, Marino A, Hervas A, Herruzo I, Ortiz MJ, Ponce de Leon J et al. Quality-of-life impact of primary treatments for localized prostate cancer in patients without hormonal treatment. J Clin Oncol. 2010; 28(31):4687-4696.

12. Jeldres C, Cullen J, Hurwitz LM, Wolff EM, Levie KE, Odem-Davis K, Johnston RB, Pham KN, Rosner IL, Brand TC, et al. Prospective quality-of-life outcomes for low-risk prostate cancer: active surveillance versus radical prostatectomy. Cancer. 2015;121(14):2465-73.

13. Chang P, Regan MM, Ferrer M, Guedea F, Patil D, Wei JT, Hembroff LA, Michalski JM, Saigal CS, Litwin MS et al. Relief of urinary symptom burden after primary prostate cancer treatment. J Urol 2016.

14. Sanda MG, Cadeddu JA, Kirkby E, Chen RC, Crispino T, Fontanarosa J, Freedland SJ, Greene K, Klotz LH, Makarov DV, et al. Clinically Localized Prostate Cancer: AUA/ASTRO/SUO Guideline. Part I: risk stratification, shared decision making, and care options. J Urol. 2018;199(3):683-90.

15. Wei JT, Dunn RL, Litwin MS, Sandler HM, Sanda MG. Development and validation of the expanded prostate cancer index composite (EPIC) for comprehensive assessment of health-related quality of life in men with prostate cancer. Urology. 2000;56(6):899-905.

16. Yang L, Kibel AS, Colditz GA, Pakpahan R, Imm KR, Izadi S, Grubb RL 3rd, Wolin KY, Sutcliffe S. Caution with use of the expanded prostate cancer index composite-50 urinary bother scale: how voiding dysfunction modifies its performance. J Urol. 2017;198(6):1397-403.

17. Skolarus TA, Dunn RL, Sanda MG, Chang P, Greenfield TK, Litwin MS, Wei JT. Minimally important difference for the Expanded Prostate Cancer Index Composite Short Form. Urology. 2015;85(1):101-5.

18. Yang L, Lee J, Kibel AS, Pernar C, Colditz GA, Pakpahan R, Imm KR, Izadi S, Grubb RL III, Wolin KY, et al. One-year urinary and sexual outcome trajectories in prostate cancer patients treated by radical prostatectomy: a prospective study. Curr Oncol. 2020;27(1):e71.

19. Romero FR, Romero AW, Filho TB, Kulysz D, Oliveira FC, Filho RT. The prostate exam. Health Educ J. 2011;71(2):239-50.

20. Barry MJ, Fowler FJ Jr, O'Leary MP, Bruskewitz RC, Holtgrewe HL, Mebust WK, Cockett AT. The American Urological Association symptom index for benign prostatic hyperplasia. The Measurement Committee of the American Urological Association. J Urol. 1992;148(5):1549-64.

21. Punnen S, Cowan JE, Chan JM, Carroll PR, Cooperberg MR. Long-term health-related quality of life after primary treatment for localized prostate cancer: results from the CaPSURE registry. Eur Urol. 2015;68(4):600-8.

22. Levinson AW, Bagga HS, Pavlovich CP, Mettee LZ, Ward NT, Link RE, Su LM. The impact of prostate size on urinary quality of life indexes following laparoscopic radical prostatectomy. J Urol. 2008;179(5):1818-22.

23. Buttyan R, Chen MW, Levin RM. Animal models of bladder outlet obstruction and molecular insights into the basis for the development of bladder dysfunction. Eur Urol. 1997;32(Suppl 1):32-9.

24. Levin RM, Haugaard N, O'Connor L, Buttyan R, Das A, Dixon JS, Gosling JA. Obstructive response of human bladder to BPH vs. rabbit bladder 
response to partial outlet obstruction: a direct comparison. Neurourol Urodyn. 2000;19(5):609-29.

25. Fusco F, Creta M, De Nunzio C, lacovelli V, Mangiapia F, Li Marzi V, Finazzi Agro E. Progressive bladder remodeling due to bladder outlet obstruction: a systematic review of morphological and molecular evidences in humans. BMC Urol. 2018;18(1):15.

26. Badr $\mathrm{H}$, Taylor CL. Sexual dysfunction and spousal communication in couples coping with prostate cancer. Psychooncology. 2009;18(7):735-46.

27. Pazmany E, Bergeron S, Verhaeghe J, Van Oudenhove L, Enzlin P. Dyadic sexual communication in pre-menopausal women with self-reported dyspareunia and their partners: associations with sexual function, sexual distress and dyadic adjustment. J Sex Med. 2015;12(2):516-28.
28. Zhao C, Kwan Park J. Phosphodiesterase type 5 inhibitor and erectile dysfunction in lower urinary tract symptoms. Lower Urinary Tract Symptoms. 2012;4(Suppl 1):75-80.

29. Mirone V, Sessa A, Giuliano F, Berges R, Kirby M, Moncada I. Current benign prostatic hyperplasia treatment: impact on sexual function and management of related sexual adverse events. Int J Clin Pract. 2011;65(9):1005-13.

\section{Publisher's Note}

Springer Nature remains neutral with regard to jurisdictional claims in published maps and institutional affiliations.
Ready to submit your research? Choose BMC and benefit from:

- fast, convenient online submission

- thorough peer review by experienced researchers in your field

- rapid publication on acceptance

- support for research data, including large and complex data types

- gold Open Access which fosters wider collaboration and increased citations

- maximum visibility for your research: over 100M website views per year

At BMC, research is always in progress.

Learn more biomedcentral.com/submissions 